\title{
Basic Movements of The Split Leap Rhythmic Gymnastics
}

\author{
Ranu Baskora Aji Putra ${ }^{1}$, Tommy Soenyoto ${ }^{2}$, Agus Darmawan ${ }^{3}$, Roas Irsyada ${ }^{4}$ \\ \{ranu_baskora@mail.unnes.ac.id ${ }^{1}$, tommysoenyoto@mail.unnes.ac.id ${ }^{2}$, \\ agus.putri12@gmail.com $\left.{ }^{3}\right\}$ \\ Universitas Negeri Semarang, Semarang, Indonesia ${ }^{1234}$
}

\begin{abstract}
The perfection of the Split Leap movement in a series of rhythmic gymnastics contributes an assessment of the optimal performance of a rhythmic gymnastics athlete. The purpose of this study was to examine the Split Leap movement in rhythmic gymnastics in physiological, biomechanical and athlete rhythmic gymnastics performance studies. This study using the Systematic mapping study methods. Writing about this split jump is analyzed using articles and books that are relevant to the topic of study that have been mapped before. Five databases were sought for empirical research published between 2003 and 2020. The study map was drawn from various reviews on the part of the connection with a review of research results and articles on topics around the SL movement as many as 41 articles. The relationship between strength, leg flexibility, range of motion , understanding of motion techniques and Physiological support are key to split leap motion.
\end{abstract}

Keywords: Split Leap, Rhythmic Gymnastics, and Split Jump.

\section{Introduction}

Rhythmic gymnasts have a basis for movement which will later be combined with rhythm. The basic motion absolutely must be mastered in the form of balletshaped free hand movements. Ballet movements include spinning, bending, balance, stepping, and jumping movements. The basic movement of a jump consists of two types of jumps using two legs and one foot, many of which can be formed from the base of this jump one of the most preferred and beautiful looks of split leap (SL). SL is a jumping motion that can use two legs when take off and swing one foot forward and the other backward so that when flying both legs stretch wide. [1,2] In beginner athletes, the SL movement is very difficult, this is due to factors supporting SL mastery of motion not yet optimally developed. The supporting factors are the physical component of explosive power, leg flexibility and improper SL movement techniques. A trainer is required to handle and direct it through a continuing training program.. The purpose of this article is to describe and study the split leap move examine the Split Leap movement in rhythmic gymnastics in physiological, biomechanical and athlete rhythmic gymnastics performance studies in various reviews based on a literature review of articles and books. 


\section{Methods}

The method used in this study is the Systematic mapping study. This paper presents a study of 4 main areas of study, namely about rhythmic gymnastics athletes, gymnast physical conditions, split jumps, and motion techniques. Articles found and peer reviewed were identified by the search engines PubMed, Crossref, Google Scholar articles, Scopus and publications by local universities from 2009 to 2020. Here is a concept map of this study approach

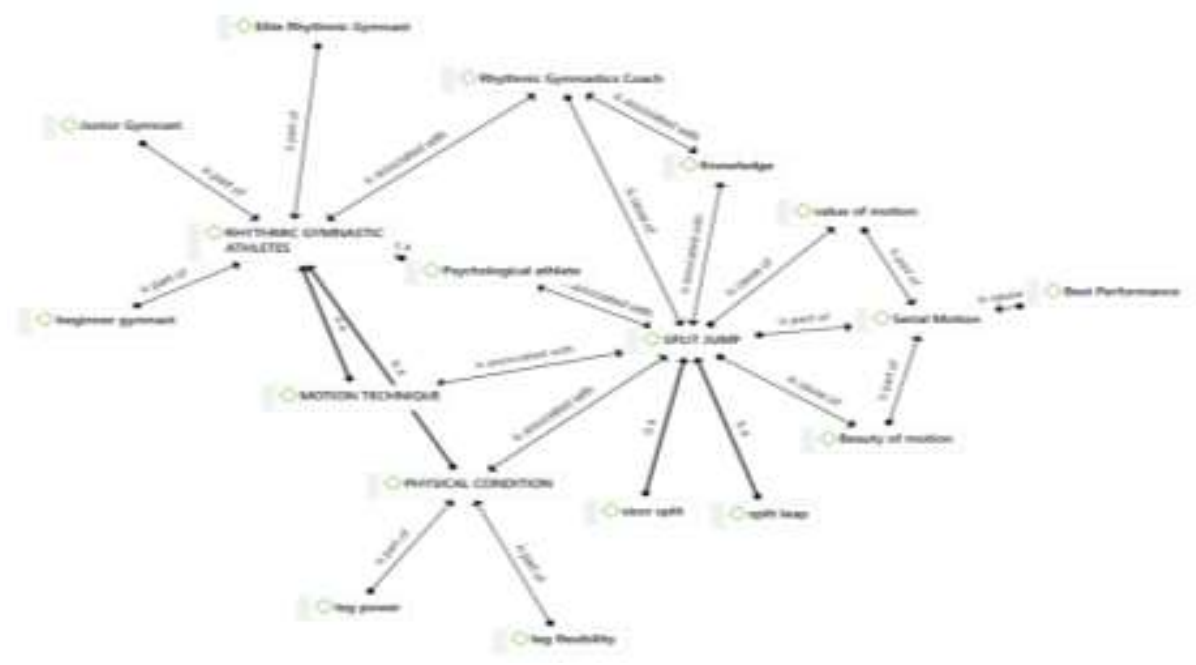

Fig. 1. Inter Connection Concept Map Field of study

\section{$3 \quad$ Results And Discussions}

The following paragraphs are a summary of the review of articles from 4 main areas. the interest of this research will be a whole study material about the split leap movement by rhythmic gymnasts to make the knowledge and consideration of sports observers, coaches and athletes of rhythmic gymnastics

\subsection{Study on Rhythmic Gymnastics Athletes}

Rhythmic gymnastics (RG) is gymnastics whose movements are arranged using rhythm. Movement in RG is a series of movements that includes beauty [3], harmony with the music in harmony.[4]. Continuous and repetitive training is needed by someone who studies SR. Rhythmic gymnasts are divided into several levels, beginner level, junior level and elite athlete.[5,6] The characteristics of the beginner gymnast begin with the start of SR learning usually for the purpose of optimal achievement starting at age 7 to 9 years. At that age where the physical components have not developed much, for example strength, speed at that age has a high flexibility and 
flexibility so that it is easy to form. The next level is the middle age of 9-12 years with the characteristics of skills that begin to develop in basic movements, the advanced level of the age of 12-14 years some of the ability to move has been well mastered. Junior age ranges from 14-16 years, where a lot of vocabulary is supported by physical and anthropometric abilities that support his skills. While the Senior Level is more than 16 years old, where the development of motion, physical abilities, anthropometrics has adapted to become a professional rhythmic gymnast. In rhythmic gymnastics athletes coordinating motion, static balance, dynamic balance, the reaction develops rapidly compared to other physical items. [7]. In rhythmic gymnastics athletes coordinating motion, static balance, dynamic balance, the reaction develops rapidly compared to other physical items.[8,9]

\subsection{Physical Conditions of Rhythmic Gymnasts}

The dominant physical components of SR include anthropomterics in the form of body composition which tends towards lean (ectcomorphic)[10,11] and sleek with an average delayed menarche [12,13], flexibility of the body in the form of passive and dynamic, range of motion for each joint in the optimal category.[14,15], coordination [6,16-17], speed, accuracy and reaction.[18]. In rhythmic gymnastics athletes coordinating motion, static balance, dynamic balance, rapidly developing reactions compared to other physical items [7,19-20]. According to research [21] that the physical component for rhythmic gymnast influences the appearance of as much as $15 \%$ of all other components which include psychology, levels of motion techniques, competitive experience, personality styles, difficulty factors, understanding music and intelligence levels.

\subsection{Rhythmic Gymnastic Motion Techniques}

At this level the peak rhythmic gymnast achievement is seen and achieved. Like most gymnastics, RG has elements that will be judged in its appearance, namely the artistic side, the series fused, the music and its movements, and the expression [3]. In an RG official race a gymnast is judged by several judges with the following criteria. The arithmetic judge judges in general the choreography of a series of movements in general including the quality of foot skills. Jury D (difficulty) assesses the benchmark final value based on the applicable Code of Point (CoP). Whereas Jury E (Execution) supervises errors of movement both in terms of artistic and technical errors of motion. From these consequences rhythmic gymnasts are expected to have perfect skills both in terms of movement techniques and choreography of the series. In order to achieve high movement techniques the gymnast should have a solid foundation of motion. Basic movements that must be mastered perfectly so that the development of vocabulary variation reaches optimal motion. The basis of rhythmic gymnastic motion is not much different from the dominant pattern of motion in gymnastics in general, namely landing, rotation, jumping, pedestal (static position), locomotor, non-locomotor and manipulative. Rhythmic gymnastics landing is one of the important techniques, landing in SR includes foot landing, landing with rotation, landing with back, etc. 


\subsection{Split Jump}

Split jumping is one of the movements that has beauty, and the appearance of motion that shows the flexibility and flexibility of a joints as wide as possible. Research says that static rhythmic gymnast. Split Jump Movement is essentially a movement stretching the width of the legs to the limits of the ability to stretch the joints. The rhythmic gymnast requires heating both static and dynamic joints in order to stretch the stretching will reduce imperfections in split leap.[22,23] The types of split jumps are Split leap, Stag leap, wallmonkeys, scissors leap.
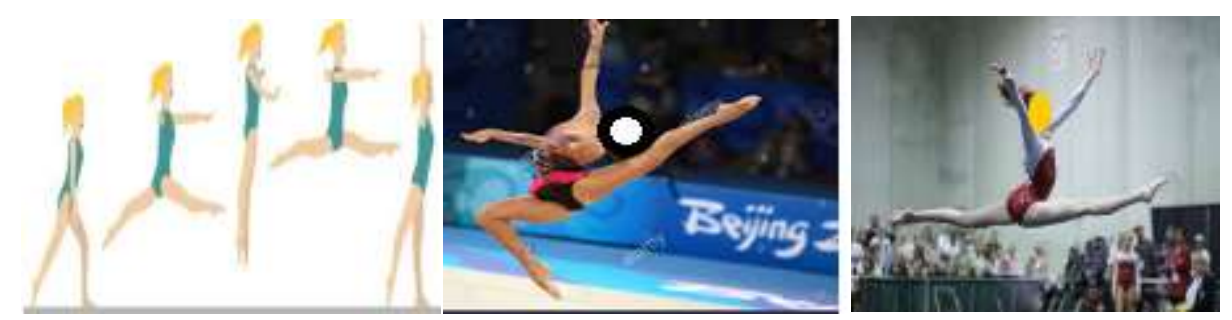

Fig. 2. scissors leap, Stag Leap, split lep.

Split leap in the appearance of motion is divided into 3 namely the preparation phase, the floating phase and the final phase (landing). In the preparation phase / prefix begins with a vertical jump using bent / semisquat limbs. Pressing the floor and rejecting it in an elastic way can quickly move the weight point. The sudden movement of limbs against gravity causes us to be able to float. But it starts with locomotor motion with polka or gallop. [24]

The gymnast's floating phase forms the legs stretching to the maximum and ready to land. This phase of style leap can be done using stag leap, split leap or something else. the strength, flexibility and coordination of the gymnast is crucial in this floating phase of $65 \%$.[25]

The gymnast's landing phase reduces speed and stabilizes the body using leg muscle strength and a good body balancing ability followed by preparing to land on the mat using legs to resist gravity. Split jumping can also be done using tools or without tools. The appearance of a rhythmic gymnast in a split jump will be maximized if done without using a tool.[26]

\subsection{Split Jump Biomechanics Study}

Split leap in the initial phase requires movement to move with a certain speed. split leap start speed.[27] To see the speed of the prefix, use the moving formula $\mathrm{V}=\frac{s}{t}$ the unit ${\mathrm{m} . \mathrm{s}^{-}}^{1}$

information $\mathrm{s}=$ distance traveled ( $\mathrm{m}$ meters), $\mathrm{t}=$ time (seconds) traveled. The initial speed of the gymnast can be in the form of a jog, sase, or other steps. The initial speed will determine the success of the core movement.[28] Each gymnast who initiates can feel the right time to change the initial speed into another movement. In 
accordance with Newton's law the object will remain stationary or move at a constant speed if there is no force acting on it.[29]

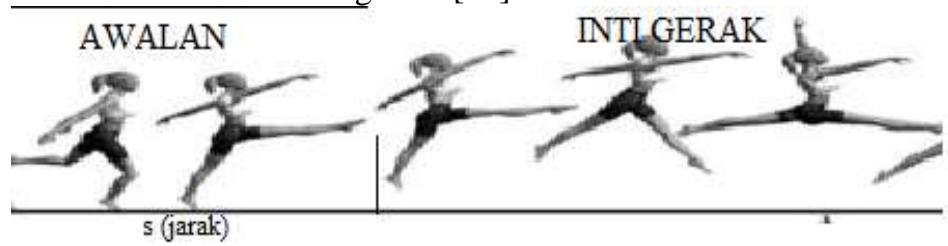

Fig. 3. Prefix Speed Before Split Jumpt

In the core phase, the gymnast's movement will change the forward horizontal momentum towards the vertical direction (above). This is where the role of gymnast explosive power is needed in the calculation of biomechanical force $(F)=m$. a Newton's unit where $\mathrm{m}$ is the gymnast's mass, $\mathrm{a}$ is its acceleration. [30] The acceleration obtained by the gymnast from the split jump prefix can be calculated by the formula $\mathrm{a}=\frac{V}{t}$ unit $\mathrm{m} \cdot \mathrm{s}^{2}$. In accordance with Newton's third law that the vertical force downward when the foot hits the mat, the mat will give the same amount of force and the opposite direction that is above the air. Furthermore, the gymnast will display split movements when floating in the air It was then that the leg joint flexibility played a role in spreading its width so that the angle of range of motion was about $180^{\circ}$. Rhythmic gymnasts would be reduced in value by judges if the leg ROM was less than $180^{\circ}$ range and it was not even acknowledged at all that the movement was a split leap. Research [22] stated that the reduction in the value of the split leap movement that was most caused by the jury was due to the moment of hovering by 0.9 connectedness with its appearance, compared to the length of the jump, ankle point and landing time. As in Figure 4 the following is a reduction by a jury:

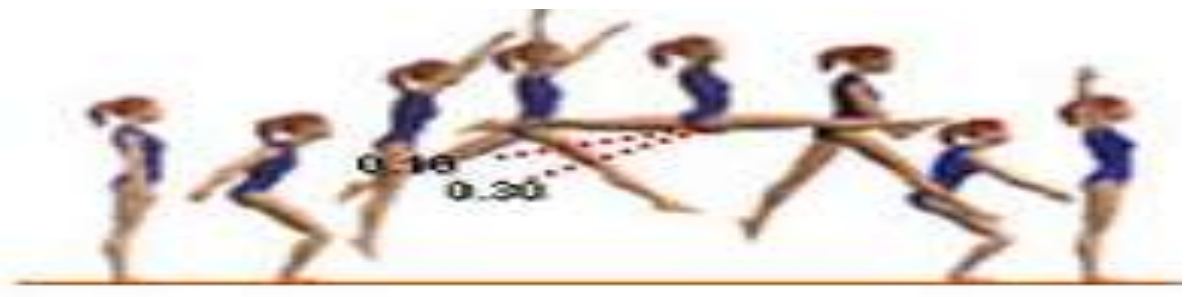

Fig. 4. Reduction in value by judges during Split Leap

The final phase of the split leap movement is landing. This phase is essentially a reduction in the forces acting on the body to fight the force of gravity so that the body is stable and balanced both in silence and will be arranged in the next movement. Research[27] states that leg strength must be met in order for a balanced landing for a series of movements, the maximum peak torque sequence from highest to lowest values is found in the hips $(5.81 \pm 1.06 \mathrm{Nm} / \mathrm{kg})$, ankles $(3.56 \pm 0.71 \mathrm{Nm} / \mathrm{kg})$ and knees $(2.01 \pm 0.75 \mathrm{Nm} / \mathrm{kg})$ Whereas for a split leap landing at rest a greater leg force is required $(5.69 \pm 2.45 \mathrm{kN} / \mathrm{m})$. 


\subsection{Split Leap Physiological Studies}

The beauty of a split leap performed by a rhythmic gymnast cannot be separated from the slender rhythmic gymnast's posture with an average level of legs.[31,32] The physical development of the gymnast to become leaner, better coordinated and strong is the result of a long training process. So that the beginning of rhythmic gymnastics exercises determine its physical development. Gymnasts who start training at the age of 6 years will have better development of movement when compared to older ones as the beginning of training if the speed of learning and portion of training are the same. This is due to the practice habits that will foster physiological adaptations from an early age regarding bone density [33], less fat percentage [34], and efficiency in moving due to the development of the nervous system.[35]. Courage and persistence in learning split leap movements will facilitate the rhythmic gymnast in arranging all movements and harmonizing with musical accompaniment. From the psychological side it will also affect that the length of rhythmic gymnastics will have a positive influence on how the gymnast organizes the stresses that have metabolic and physiological effects.[36]. Satisfaction and awareness of the gymnast's body porposi will affect the attitude and appearance in rhythmic gymnastics.[37,38] Courage and persistence in learning split leap movements will facilitate the rhythmic gymnast in arranging all movements and harmonizing with musical accompanimen

\subsection{Coach support}

Foresight of the trainer in making an exercise program with a sufficient portion of training also contributes greatly to each success in the performance of rhythmic gymnastics athletes. Rhythmic gymnastics trainers have specific specifications in knowledge such as choreography of movements, selection and editing of music and play a role in athlete training sessions.[21] Professional trainers equip themselves with a variety of knowledge [39] about motion mechanics, psychology [40], physiology and even about handling injuries.[41] The trainer will always coordinate continuously with parents to continue to monitor the development of the training program provided to see the effect of the exercise on attitude, mental, physiological adaptation and cognitive development outside of the exercise. Good cooperation between parents and trainers in supporting gymnasts will improve the development of performance / appearance in their careers on rhythmic gymnastics. The appearance of a rhythmic gymnast with a variety of movements having a high difficulty factor is in harmony with the accompanying music so that capturing the attention of the jury and the audience is the ultimate goal of a training. But the actual impact of long training will provide tremendous benefits for the development of the overall potential of a rhythmic gymnast in terms of physical, anthropometric, mental, knowledge and social. 


\section{Conclusion}

Split leap is part of the motion element of a series of movements performed by a rhythmic gymnast. A beauty of movement that involves all the potential rhythmic gymnasts who develop towards the perfection of his appearance optimally. The relationship between strength, leg flexibility, range of motion and understanding of motion techniques are key to split leap motion. Further research is needed on how much the contribution of physical factor proportions, psychology and technical understanding of the appearance of split leap movementsThe effects of split leap training will provide benefits for the potential development of gymnastics athletes, increase knowledge and vocabulary of movement in a series of rhythmic gymnastic movements.

\section{References}

[1]. Cicchella A. Kinematics analysis of selected rhytmic gymnastic leaps. J Hum Sport Exerc. 2009;

[2]. Purenović T, Bubanj S, Popović R, Stanković R, Bubanj R. Comparative kinematics analysis of different split front leaps. Sport Sci. 2010;

[3]. Kritikou M, Donti O, Bogdanis GC, Donti A, Theodorakou K. Correlates of artistry performance scores in preadolescent rhythmic gymnasts. Sci Gymnast J. 2017;

[4]. Chiat LF, Ying LF. Importance of Music Learning and Musicality in Rhythmic Gymnastics. Procedia - Soc Behav Sci. 2012;

[5]. Zisi V, Giannitsopoulou E, Vassiliadou O, Pollatou E, Kioumourtzoglou E. Performance level, abilities and psychological characteristics in young junior rhythmic gymnasts: The role of sport experience. Int Q Sport Sci. 2009;

[6]. Purenović-Ivanović T, Popović R, Stanković D, Bubanj S. THE IMPORTANCE OF MOTOR COORDINATION ABILITIES FOR PERFORMANCE IN RHYTHMIC GYMNASTICS. Phys Educ Sport. 2016;

[7]. Zisi V, Giannitsopoulou E, Vassiliadou O, Pollatou E, Kioumourtzoglou E. Performance level, abilities and psychological characteristics in young junior rhythmic gymnasts: The role of sport experience. Int Q Sport Sci. 2009;4:1-13.

[8]. Purenović-Ivanović T, Popović R, Bubanj S, Stanković R. Body composition in highlevel female rhythmic gymnasts of different age categories. Sci Sport. 2019;

[9]. Piazza M, Battaglia C, Fiorilli G, Innocenti G, Iuliano E, Aquino G, et al. Effects of resistance training on jumping performance in pre-adolescent rhythmic gymnasts: A randomized controlled study. Ital J Anat Embryol. 2014;

[10]. Purenović-Ivanović T, Popović R. Somatotype of top-level Serbian rhythmic gymnasts. J Hum Kinet. 2014;

[11]. Klentrou P, Plyley M. Onset of puberty, menstrual frequency, and body fat in elite rhythmic gymnasts compared with normal controls. Br J Sports Med. 2003;

[12]. Ávila-Carvalho L, Klentrou P, Palomero M da L, Lebre E. Body composition profile of elite group rhythmic gymnasts. Sci Gymnast J. 2012; 
[13]. Czajkowska M, Plinta R, Rutkowska M, Brzęk A, Skrzypulec-Plinta V, Drosdzol-Cop A. Menstrual cycle disorders in professional female rhythmic gymnasts. Int J Environ Res Public Health. 2019;

[14]. Santos AB, Lemos ME, Lebre E, Carvalho LÁ. Active and passive lower limb flexibility in high level rhythmic gymnastics. Sci Gymnast J. 2015;

[15]. Luo L. Study on Quality Indicator System of Rhythmic Gymnasts in Analytic Hierarchy Process. In: IOP Conference Series: Earth and Environmental Science. 2017.

[16]. Rehab Hafez A. IMPACT OF COORDINATION ABILITIES PROGRAM ON ACCURACY AND SPEED IN RHYTHMIC GYMNASTICS. Romania The journal is indexed in: Ebsco, SPORTDiscus, INDEX COPERNICUS JOURNAL MASTER LIST. 2016.

[17]. Ferro-sánchez A, Galan MR, Villacieros J. Analysis of the coordination and the sequence of corporal movements in the split jump of rhythmic gymnastics. In: XXXVI Congress of the Iberian Society of Biomechanics and Biomaterials. 2013.

[18]. Giannitsopoulou E, Zisi V, Kioumourtzoglou E. Elite performance in rhythmic gymnastics: Do the changes in code of points affect the role of abilities? J Hum Mov Stud. 2003;

[19]. Di Cagno A, Battaglia C, Fiorilli G, Piazza M, Giombini A, Fagnani F, et al. Motor learning as young gymnast's talent indicator. J Sport Sci Med. 2014;

[20]. Sobera M, Rutkowska-Kucharska A. Postural Control in Female Rhythmic Gymnasts in Selected Balance Exercises: A Study of Two Cases. Polish J Sport Tour. 2019;

[21]. Qiong X. Analysis of influencing factors on performance of rhythmic gymnasts. In: Advanced Materials Research. 2013.

[22]. Rodríguez Galán LM, Gómez-Landero Rodríguez LA. Performance variables and technical penalties of the split leap. Rev Int Med y Ciencias la Act Fis y del Deport. 2018;

[23]. A. DC, C. B, C. B, M.C. G, M. V, M. P, et al. Preexercise static stretching effect on leaping performance in elite rhythmic gymnasts. Journal of Strength and Conditioning Research. 2010.

[24]. Borisova V V., Titova A V., Shestakova TA. Special footwork quality improvement method for junior rhythmic gymnasts. Teor i Prakt Fiz Kult. 2019;

[25]. Miletic D, Sekulic D, Wolf-Cvitak J. The leaping performance of 7-year-old novice rhythmic gymnasts is highly influenced by the condition of their motor abilities. Kinesiology. 2004;

[26]. Mkaouer B, Amara S, Tabka Z. Split leap with and without ball performance factors in rhythmic gymnastics. Sci Gymnast J. 2012;

[27]. Bąkiewicz M, Kẹpczyński A, Wit A. Comparative Analysis of Kinetics Parameters during Different Landing after Split Front Leaps. Polish J Sport Tour. 2019;

[28]. Coppola S, Albano D, Sivoccia I, Vastola R. Biomechanical analysis of a rhythmic gymnastics jump performed using two run-up techniques. J Phys Educ Sport. 2020;

[29]. Ruíz AAB. Sports Biomechanic [Internet]. Vol. 3. 2015. 54-67 p. Available from: http://repositorio.unan.edu.ni/2986/1/5624.pdf

[30]. Batista A, Garganta R, ávila-Carvalho L. Strength in young rhythmic gymnasts. J Hum Sport Exerc. 2017;

[31]. Tringali C, Brivio I, Stucchi B, Silvestri I, Scurati R, Michielon G, et al. Prevalence of a characteristic gene profile in high-level rhythmic gymnasts. J Sports Sci. 2014; 
[32]. Di Cagno A, Baldari C, Battaglia C, Guidetti L, Piazza M. Anthropometric characteristics evolution in elite rhythmic gymnasts. Ital J Anat Embryol. 2008;

[33]. Tournis S, Michopoulou E, Fatouros IG, Paspati I, Michalopoulou M, Raptou P, et al. Effect of rhythmic gymnastics on volumetric bone mineral density and bone geometry in premenarcheal female athletes and controls. J Clin Endocrinol Metab. 2010;

[34]. Galetta F, Franzoni F, D’Alessandro C, Piazza M, Tocchini L, Fallahi P, et al. Body composition and cardiac dimensions in elite rhythmic gymnasts. J Sports Med Phys Fitness. 2015;

[35]. Mawase F, Shmuelof L, Bar-Haim S, Karniel A. Savings in locomotor adaptation explained by changes in learning parameters following initial adaptation. J Neurophysiol. 2014;

[36]. Kolbe I, Dumbell R, Oster H. Circadian clocks and the interaction between stress axis and adipose function. International Journal of Endocrinology. 2015.

[37]. Stirling AE, Cruz LC, Kerr GA. Influence of Retirement on Body Satisfaction and Weight Control Behaviors: Perceptions of Elite Rhythmic Gymnasts. J Appl Sport Psychol. 2012;

[38]. Soric M, Misigoj-Durakovic M, Pedisic Z. Dietary intake and body composition of prepubescent female aesthetic athletes. Int J Sport Nutr Exerc Metab. 2008;

[39]. He C, Trudel P, Culver DM. Actual and ideal sources of coaching knowledge of elite Chinese coaches. Int J Sport Sci Coach. 2018;

[40]. Álvarez O, Falco C, Estevan I, Molina-García J, Castillo I. Psychological intervention in a rhythmic gymnastics team: A case study. Rev Psicol del Deport. 2013;

[41]. Cavallerio F, Wadey R, Wagstaff CRD. Understanding overuse injuries in rhythmic gymnastics: A 12-month ethnographic study. Psychol Sport Exerc. 2016; 